\title{
Predictive value of respiratory symptoms for the diagnosis of pollen-induced seasonal asthma among children and adults in Inner Mongolia
}

This article was published in the following Dove Press journal:

Therapeutics and Clinical Risk Management

4 August 2017

Number of times this article has been viewed

\author{
Ting Ting $\mathrm{Ma}^{\mathrm{I}-3}$ \\ Yan Zhuang' \\ Hai Ying Gong ${ }^{4}$ \\ Anthony Chauang $\mathrm{Yii}^{5}$ \\ Xue Yan Wang' \\ Huan Zhong Shi ${ }^{2,3}$ \\ 'Department of Allergy, Beijing \\ Shijitan Hospital, Capital Medical \\ University, ${ }^{2}$ Department of \\ Respiratory and Critical Care \\ Medicine, Beijing Chao-Yang Hospital, \\ Beijing Institute of Respiratory \\ Medicine, Capital Medical University, \\ ${ }^{3}$ Center of Medical Research, Beijing \\ Institute of Respiratory Diseases, \\ ${ }^{4}$ Fangshan District Center for Disease \\ Control and Prevention, Beijing, \\ China; ${ }^{5}$ Department of Respiratory \\ and Critical Care Medicine, Singapore \\ General Hospital, Singapore, \\ Singapore
}

Background: The diagnosis of asthma is made on the basis of variable respiratory symptoms and supported by objective evidence of variable airflow limitation. However, spirometry and bronchoprovocation tests may not be routinely available in resource-scarce settings or in the context of large-scale epidemiological studies. There is a gap in knowledge about the predictive value of respiratory symptoms for the diagnosis of pollen-induced asthma.

Objective: The aim of this study was to investigate the predictive value of self-reported respiratory symptoms for diagnosing pollen-induced asthma.

Patients and methods: We recruited 1,161 patients with respiratory symptoms who presented to the respiratory medicine outpatient clinic of two central hospitals in Inner Mongolia during the pollen season of July-September 2015. All patients were interviewed by a respiratory physician and completed a questionnaire survey, lung function tests and skin prick tests for common inhaled allergens.

Results: A total of 392 patients (33.8\%) were diagnosed with asthma and 292 (25.2\%, 160 adults, 132 children) with pollen-induced asthma. Respiratory symptoms of cough, wheezing, dyspnea, chest pain and nocturnal awakenings due to breathlessness were all associated with increased odds of being diagnosed with pollen-induced asthma, with cough being the most common symptom in both adults and children, giving a sensitivity of $90.6 \%$ in adults and $88.6 \%$ in children. Wheezing was the most specific symptom $(78 \%$ and $89.5 \%$ in adults and children, respectively) compared to other symptoms. Overall, the positive predictive value of respiratory symptoms was poor for diagnosing pollen-induced asthma, with the exception of wheezing in children which had a high positive predictive value of $72.7 \%$.

Conclusion: Cough was the predominant symptom in adults and children with pollen-induced asthma. Wheezing was a reliable predictor of pollen-induced asthma in children. In adults, respiratory symptoms were not sufficiently reliable for diagnosing pollen-induced asthma.

Keywords: pollen-induced asthma, asthma symptoms, wheezing, cough, shortness of breath

Correspondence: Huan Zhong Shi Department of Respiratory and Critical Care Medicine, Beijing Chao-Yang Hospital, No 8, Workers Stadium South Road, Chaoyang District,

Beijing 100020, China

Tel +86 I0 8523 I409

Emailm1391/612465_I@I63.com

Xue Yan Wang

Department of Allergy, Beijing Shijitan Hospital, No 10, Yang Fang Dian Road, Haidian District, Beijing I00038, China

Tel +861063926072

Email wangxueyan2018@I63.com

\section{Introduction}

Asthma is one of the most common chronic respiratory diseases worldwide and represents an important source of health care costs. In recent years, there has been a rise in the incidence and mortality of asthma. Globally, about 300 million people are afflicted with asthma, with 250,000 deaths every year. ${ }^{1-3}$ Asthma poses a major burden not only on patients but also on health care systems. ${ }^{4-6}$ Identifying patients who suffer from asthma and preventing and controlling disease are major challenges faced currently.

Asthma is a highly heterogeneous disease with variable and diverse symptomology, inflammatory phenotypes, airway physiology and pathobiologic pathways. Wheezing, 
shortness of breath, chest tightness and cough are the most frequent symptoms of asthma, ${ }^{7-9}$ and symptoms are important for diagnosing asthma and monitoring disease activity. The Global Initiative for Asthma (GINA) has established criteria for the diagnosis of asthma which encompasses two components: a history of variable respiratory symptoms and evidence of variable expiratory airflow limitation. ${ }^{9}$ While important for providing supporting evidence for making the diagnosis of asthma, lung function tests such as spirometry, bronchodilator reversibility and bronchoprovocation testing are not specific for asthma, can be falsely negative and cannot be used as exclusive criteria for diagnosing asthma. In addition, lung function tests may not be available in resource-scarce settings where achieving a clinical diagnosis of asthma depends on careful history, examination and exclusion of other respiratory diseases. Global large-scale epidemiological surveys often rely on symptom questionnaires to diagnose asthma because of cost reasons, convenience and difficulty with standardizing and performing lung function tests. For example, in a largest worldwide collaborative research project of the International Study of Asthma and Allergies in Childhood (ISAAC), ${ }^{10,11}$ the core questionnaires are mainly concerned with the respiratory symptoms such as wheezing throughout the year, which implies the primary importance of respiratory symptoms.

The validity of using symptoms to distinguish between asthmatics and non-asthmatics is questionable. Symptoms and signs such as cough, rhonchi, wheezing, chest tightness and shortness of breath are nonspecific manifestations of a broad range of pulmonary and non-pulmonary diseases, including but not limited to asthma, chronic obstructive pulmonary disease (COPD), acute bronchitis, bronchiectasis ${ }^{11-14}$ and cardiac disease. Little is known about the sensitivity, specificity and predictive values of these common respiratory symptoms in relation to asthma diagnosis, especially in seasonal polleninduced asthma, a unique phenotype of asthma linked to high ambient concentrations of allergenic pollen which can occur as outbreaks/epidemics and has been described in various geographic regions worldwide. ${ }^{15-17}$ Hence, we performed a prospective study of pollen-induced asthma in a grassland area (Inner Mongolia Autonomous Region, China). High pollen counts of Artemisia species, Humulus scandens and Chenopodiaceae occur seasonally in July-September and are paralleled by increased numbers of patients presenting with asthma and other allergic diseases. The aim of this study was to investigate the relationship between the presence of common respiratory symptoms and clinically confirmed pollen-induced asthma in both adults and children.
We also aimed to evaluate the sensitivity, specificity and positive and negative predictive values of respiratory symptoms for diagnosing pollen-induced asthma.

\section{Patients and methods}

This was a cross-sectional study. Approval to conduct this study was obtained from the ethics committees of the Beijing Shijitan Hospital and the Tongliao City Hospital (China). All study participants provided written informed consent prior to recruitment.

From July to September 2015, all subjects who presented to the respiratory medicine outpatient clinics of two Tongliao City Hospitals with one or more symptoms of cough, wheezing, chest tightness or shortness of breath were invited to participate in the study. Following recruitment, subjects completed a standardized questionnaire administered by a respiratory physician asking about gender, age, place of residence (urban and rural), ethnic group (Han, Mongolian and others), body mass index (BMI), respiratory symptoms on a month-to-month basis in the past 12 months (wheezing, cough, shortness of breath, chest tightness and nocturnal awakenings), smoking history, allergy to food, family history of allergies/allergic diseases, living conditions, environmental exposure and others.

All participants underwent lung function tests and skin prick tests (SPTs) with a panel of common respiratory aeroallergens. Asthma was diagnosed according to GINA 2014 guidelines, requiring the history of both variable respiratory symptoms and variable expiratory airflow limitation (positive bronchodilator reversibility of $>12 \%$ and $200 \mathrm{~mL}$ after $200-400 \mu \mathrm{g}$ of salbutamol, or average diurnal peak flow variability $>10 \%$ in adults or $>13 \%$ in children). ${ }^{13}$ Polleninduced asthma was diagnosed based on the history of onset of symptoms in relation to exposure of the pollen allergens which were reported by local pollen counts in time and with IgE-mediated sensitization confirmed by SPTs. Systematic assessment to exclude the following diseases was carried out before making a diagnosis of asthma or pollen-induced asthma: COPD, interstitial lung disease or pulmonary fibrosis, bronchiectasis, lung cancer, pneumonia, pneumothorax, pulmonary embolism, allergic bronchopulmonary aspergillosis, heart diseases and gastroesophageal reflex disease. Patients were excluded from the study if they had previously received immunotherapy.

\section{SPTs}

SPTs were conducted by trained allergy nurses or physicians. Oral antihistamines were discontinued for at least 3 days 
prior to SPT. Ten respiratory aeroallergens such as Artemisia species, Chenopodium, Humulus scandens, Salix, Zea mays, Juniperus chinensis var. chinensis, Ulmus pumila, Betula, Populus, and Dermatophagoides pteronyssinus (DP) were tested using standardized allergen extracts (Macro-Union Pharmaceutical Co., Ltd., Beijing, China). The diluent was administered as negative control and histamine hydrochloride $(1 \mathrm{mg} / \mathrm{mL})$ as positive control. Allergen extracts were administered to the flexor side of forearm unilaterally after disinfection with alcohol at a distance of $1.5 \mathrm{~cm}$ using a disposal skin test needle. The reaction of patients was observed 15 min later. Wheal diameter of $\geq 3 \mathrm{~mm}$ for each of the allergens tested was considered as positive response. ${ }^{18}$

\section{Statistical analysis}

Epidate 3.1 (EpiData Association, Odense, Denmark) was used for data entry. Data were analyzed using SPSS 17.0 (SPSS Inc., Chicago, IL, USA). Data were reported as number (\%) for categorical variables and mean \pm standard deviation for continuous data. Univariate comparisons were performed using independent-sample $t$-test as the continuous data were normally distributed. Binary logistic regression was used to assess the association between respiratory symptoms and pollen-induced asthma. A $P$-value of $<0.05$ was considered significant.

\section{Results}

A total of 1,161 patients, 770 adults $(66.3 \%)$ and 391 children (33.7\%), were recruited. Patient characteristics are shown in Table 1. A total of 392 patients (33.7\%) were diagnosed as asthma. There was no statistical difference between asthmatic and non-asthmatic patients in terms of gender, age, ethnicity, area of residence, smoking and BMI.

Among the asthmatic patients, 292 patients (160 adults and 132 children) were confirmed to be pollen-induced asthma, and they were further analyzed for correlation between the presence of respiratory symptoms and diagnosis of pollen-induced asthma.

\section{Respiratory symptoms}

As shown in Table 2, the presence of each respiratory symptom was predictive of pollen-induced asthma in both adults and children. The presence of these symptoms reached a peak in July, August and September (Figure 1A and C), which were also the high pollen season as reported by daily local pollen counts (data not shown).

Cough was the most common symptom in both adults $(n=145,90.6 \%)$ and children $(n=117,88.6 \%)$ with polleninduced asthma. In logistic regression analyses, the three most common symptoms (Table 3 ) associated with increased

Table I Demographic characteristics of the study subjects

\begin{tabular}{|c|c|c|c|c|c|c|c|}
\hline \multirow[t]{2}{*}{ Characteristics } & \multicolumn{3}{|c|}{ Adults $(n=770)$} & \multicolumn{3}{|c|}{ Children $(n=391)$} & \multirow{2}{*}{$\begin{array}{l}\text { Total } \\
(n=I, 16 I)\end{array}$} \\
\hline & $\begin{array}{l}\text { Asthma } \\
(n=228)\end{array}$ & $\begin{array}{l}\text { Non-asthmatic } \\
(n=542)\end{array}$ & P-value & $\begin{array}{l}\text { Asthma } \\
(n=164)\end{array}$ & $\begin{array}{l}\text { Non-asthmatic } \\
(n=227)\end{array}$ & $P$-value & \\
\hline Gender & & & 0.4457 & & & 0.2150 & \\
\hline Male & $85(37.3)$ & $218(40.2)$ & & $77(47.0)$ & I2I (53.3) & & $50 \mathrm{I}(43.2)$ \\
\hline Female & $143(62.7)$ & $324(59.8)$ & & $87(53.0)$ & $106(46.7)$ & & $660(56.8)$ \\
\hline Age (years) & & & 0.0655 & & & 0.2030 & \\
\hline $6-14$ & - & - & & 150 (9l.5) & 215 (94.7) & & $365(31.4)$ \\
\hline $15-18$ & - & - & & 14 (8.5) & $12(5.3)$ & & $26(2.2)$ \\
\hline $19-44$ & I I 5 (50.4) & $267(49.3)$ & & - & - & & $382(32.9)$ \\
\hline $45-64$ & $78(34.2)$ & $220(40.6)$ & & - & - & & $298(25.7)$ \\
\hline$\geq 65$ & $35(15.4)$ & $55(10.1)$ & & - & - & & $90(7.8)$ \\
\hline Ethnicity & & & 0.2883 & & & 0.9592 & \\
\hline Han & $|4|$ (6I.8) & 302 (55.7) & & $89(54.3)$ & $122(53.7)$ & & $654(56.3)$ \\
\hline Mongolian & $80(35.1)$ & $222(41.0)$ & & $66(40.2)$ & $91(40.1)$ & & $459(39.5)$ \\
\hline Others & $7(3.1)$ & $18(3.3)$ & & $9(5.5)$ & $14(6.2)$ & & $48(4.2)$ \\
\hline Area of residence & & & 0.3557 & & & 0.0885 & \\
\hline Urban & $119(52.2)$ & $303(55.9)$ & & $90(54.9)$ & $144(63.4)$ & & $656(56.5)$ \\
\hline Rural & 109 (47.8) & $239(44.1)$ & & $74(45.1)$ & $83(36.6)$ & & $505(43.5)$ \\
\hline Smoking & & & 0.0600 & & & & \\
\hline Current smoker & I 77 (77.6) & 382 (70.5) & & - & - & & $559(48.1)$ \\
\hline Never smoker & $30(13.2)$ & I I0 (20.3) & & - & - & & $140(12.1)$ \\
\hline Ex-smoker & $21(9.2)$ & $50(9.2)$ & & - & - & & $71(6.1)$ \\
\hline BMI & $24.6 \pm 4.2$ & $24.7 \pm 3.8$ & 0.712 & $18.4 \pm 5.0$ & $18.2 \pm 4.6$ & 0.6891 & $22.5 \pm 5.2$ \\
\hline
\end{tabular}

Note: Data shown as number (\%) or mean \pm standard deviation. Abbreviation: BMI, body mass index. 
Table 2 Common asthma characteristic symptoms in patients with pollen-induced asthma and non-asthmatic

\begin{tabular}{|c|c|c|c|c|c|c|}
\hline \multirow[t]{2}{*}{ Clinical symptoms } & \multirow{2}{*}{$\begin{array}{l}\text { Pollen-induced } \\
\text { asthma }(n=160)\end{array}$} & \multicolumn{2}{|l|}{ Adults $(n=702)$} & \multicolumn{3}{|l|}{ Children ( $n=359)$} \\
\hline & & $\begin{array}{l}\text { Non-asthmatic } \\
(\mathrm{n}=542)\end{array}$ & $P$-value & $\begin{array}{l}\text { Pollen-induced } \\
\text { asthma }(n=132)\end{array}$ & $\begin{array}{l}\text { Non-asthmatic } \\
(\mathrm{n}=227)\end{array}$ & $P$-value \\
\hline Cough & $145(90.6)$ & $355(65.5)$ & $<0.0001$ & $117(88.6)$ & $159(70.0)$ & $<0.000 \mathrm{I}$ \\
\hline Chest tightness & $126(78.8)$ & $34 \mid(62.9)$ & 0.0001 & $55(4 I .7)$ & $54(23.8)$ & 0.0006 \\
\hline Shortness of breath & $122(76.3)$ & $297(54.8)$ & $<0.0001$ & $49(37.1)$ & $43(18.9)$ & $<0.0001$ \\
\hline Wheezing & $98(61.3)$ & $99(18.3)$ & $<0.0001$ & $72(54.5)$ & $10(4.4)$ & $<0.0001$ \\
\hline Nocturnal awakening due to breathlessness & $89(55.6)$ & $155(28.6)$ & $<0.0001$ & $43(32.6)$ & $39(17.2)$ & 0.0005 \\
\hline
\end{tabular}

Note: Data shown as number (\%).

odds of being diagnosed with pollen-induced asthma (with adjusted odds ratio $[\mathrm{OR}]$; confidence interval $[\mathrm{CI}])$ were wheezing ( $\mathrm{OR}=7.8,95 \% \mathrm{CI}$ : 5-11.4), cough $(\mathrm{OR}=5.4$, 95\% CI: 3.2-9.6) and shortness of breath (OR $=2.6,95 \%$

A

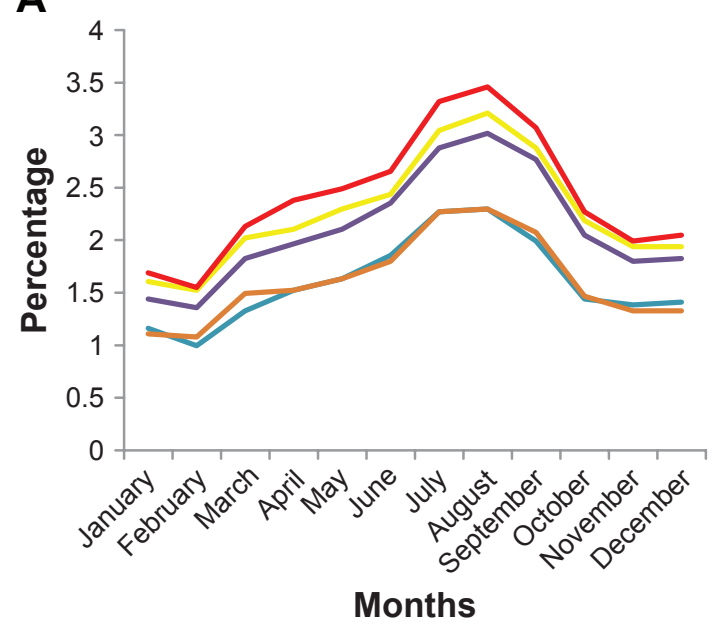

C

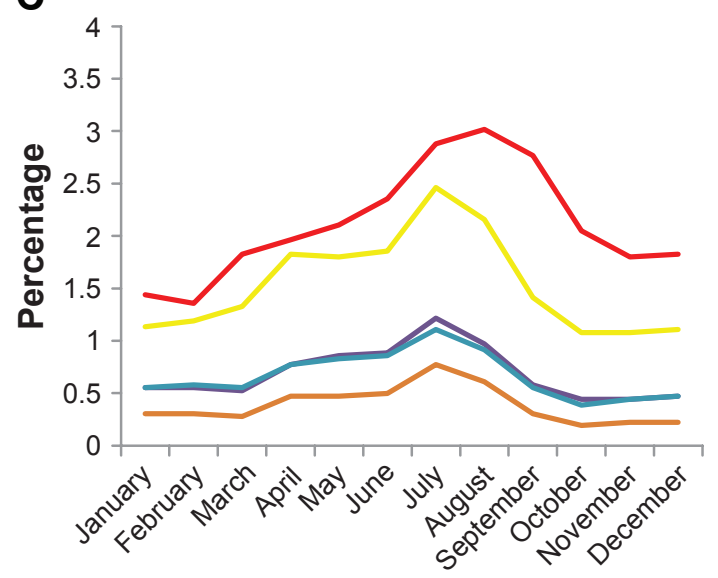

Months
CI: $1.9-4.1)$ in adults and wheezing $(\mathrm{OR}=30.6,95 \% \mathrm{CI}$ : 14.4-65.7), cough (OR $=4.4,95 \% \mathrm{CI}: 2.3-8.9)$ and shortness of breath $(\mathrm{OR}=2.7,95 \% \mathrm{CI}: 1.7-4.7)$ in children. In addition, the sensitivity and specificity, together with positive and

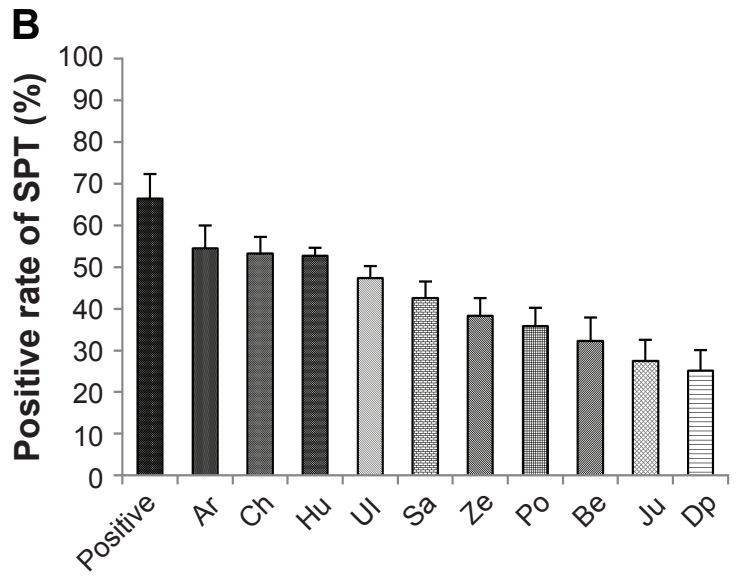

Allergen

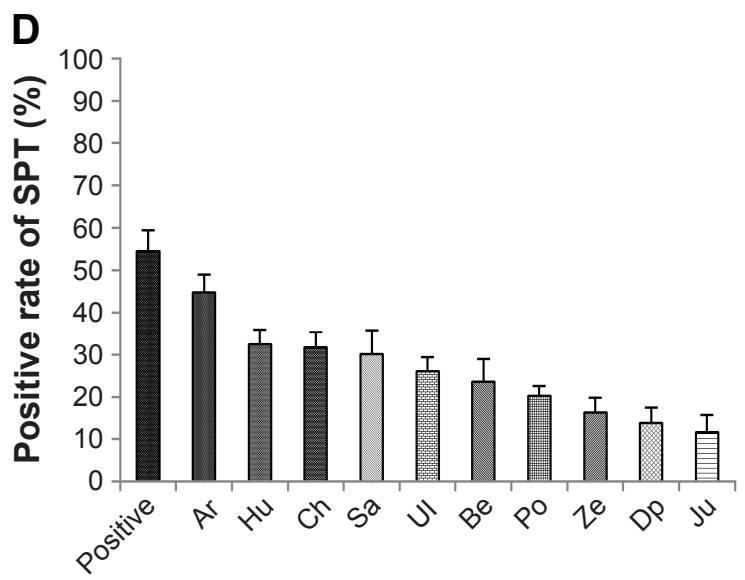

Allergen

Figure I The frequency of appearance (\%) of asthma characteristic symptoms throughout 12 months in adults (A) and children (C), and the positive rate (\%) of common inhalant allergens tested (SPT) in adults (B) and children (D).

Abbreviations: Ar, Artemisia species; Be, Betula; Ch, Chenopodium; DP, Dermatophagoides pteronyssinus; Hu, Humulus scandens; Ju, Juniperus chinensis var. chinensis; Po, Populus; Sa, Salix; SPT, skin prick test; UI, Ulmus pumila; Ze, Zea mays. 
Table 3 The correlation between common asthma characteristic symptoms and seasonal asthma in adults and children

\begin{tabular}{|c|c|c|c|c|}
\hline \multirow[t]{2}{*}{ Clinical symptoms } & \multicolumn{2}{|l|}{ Adults } & \multicolumn{2}{|l|}{ Children } \\
\hline & Crude OR (95\% Cl) & Adjusted OR $(95 \% \mathrm{Cl})$ & Crude OR $(95 \% \mathrm{Cl})$ & Adjusted OR $(95 \% \mathrm{Cl})$ \\
\hline Wheezing & $7.1(4.9-10.3)$ & $7.8(5.0-11.4)$ & $30.2(14.1-64.0)$ & $30.6(14.4-65.7)$ \\
\hline Cough & $5.2(2.7-9.1)$ & $5.4(3.2-9.6)$ & $4.4(2.3-8.9)$ & $4.4(2.3-8.9)$ \\
\hline Shortness of breath & $2.5(1.7-4.1)$ & $2.6(1.9-4.1)$ & $2.8(1.8-4.6)$ & $2.7(1.7-4.7)$ \\
\hline Chest tightness & $2.2(1.6-3.6)$ & $2.4(1.6-3.4)$ & $2.2(1.4-3.7)$ & $2.4(1.4-3.8)$ \\
\hline Nocturnal awakening due to breathlessness & $2.8(2.1-4.2)$ & $3.0(2.1-4.1)$ & $2.6(1.6-4.1)$ & $2.3(1.5-4.1)$ \\
\hline
\end{tabular}

Note: Adjusted for gender, age, smoking and BMI.

Abbreviations: $\mathrm{BMI}$, body mass index; $\mathrm{Cl}$, confidence interval; OR, odds ratio.

negative predictive values, of these respiratory symptoms for the diagnosis of pollen-induced seasonal asthma in adults and children have been calculated (Table 4). Wheezing had the highest specificity (adults: 78\%, children: $89.5 \%$ ) for polleninduced asthma. However, all the respiratory symptoms had low positive predictive values in both children and adults, with the exception of wheezing in children which demonstrated a good positive predictive value of $72.7 \%$.

\section{The pattern of allergic sensitization}

Based on SPT results, allergic sensitization (positive SPT) was $66.5 \%$ in adults (Figure 1B) and $54.5 \%$ in children (Figure 1D). The predominant sensitization patterns were Artemisia species, Humulus scandens and Chenopodiaceae, and most subjects were sensitized to at least three or more pollens (Figure 2), mirroring the pollen species count reported in the region. Interestingly, sensitization to house dust mite allergen (eg, DP) had a low prevalence compared to pollens.

\section{Discussion}

In the current study, we evaluated the predictive value of respiratory symptoms for the diagnosis of pollen-induced asthma in a cohort of adults and pediatric individuals experiencing respiratory symptoms during the pollen season of July-September 2015. Cough was the predominant symptom. Although wheezing, cough, shortness of breath, chest tightness and nocturnal symptoms were all associated with pollen-induced asthma, respiratory symptoms had a poor positive predictive value for diagnosing pollen-induced asthma in adults, indicating that assessing symptoms alone is not sufficiently reliable to identifying pollen-induced asthma cases even in a high-prevalence setting. In contrast, wheezing demonstrated good positive predictive value of $72.7 \%$ for diagnosing pollen-induced asthma in children.

Epidemiological studies of asthma are valuable for advancing our knowledge in asthma prevalence and risk factors, as well as to investigate asthma as a risk factor for the development of other disease such as COPD, lung cancer and pulmonary infections. An accurate and validated instrument to identify asthma cases is therefore crucial. Most studies have used symptoms to define asthma cases. In the Phase III study reports (2006) of the ISAAC, the rise in the prevalence of asthma in many countries is documented on the basis of positive answers to the written question: "Have you (has your child) had wheezing or whistling in the chest in the past 12 months?" 10,11 In that study, other common symptoms such as shortness of breath, chest tightness and cough were not included, and asthma diagnosis was not validated. In a Swiss population-based study reported by Sistek et al, ${ }^{19}$ wheezing was the most sensitive symptom (75\%) for an asthma diagnosis, defined as positive selfreported history of doctor-diagnosed asthma. Wheezing with dyspnea had the best, albeit modest, positive predictive value (24\%).

Table 4 Sensitivity and specificity, together with positive and negative predictive values, of these respiratory symptoms for the diagnosis of pollen-induced seasonal asthma in adults and children

\begin{tabular}{|c|c|c|c|c|c|c|c|c|}
\hline \multirow[t]{2}{*}{ Clinical symptoms } & \multicolumn{4}{|l|}{ Adults $(n=160)$} & \multicolumn{4}{|c|}{ Children $(n=132)$} \\
\hline & Sensitivity (\%) & Specificity (\%) & PPV (\%) & NPV (\%) & Sensitivity (\%) & Specificity (\%) & PPV (\%) & NPV (\%) \\
\hline Cough & 90.6 & 32.8 & 26.4 & 92.9 & 88.6 & 27.1 & 38.4 & 82.3 \\
\hline Chest tightness & 78.8 & 35.8 & 24.6 & 86.3 & 41.7 & 74.4 & 45.4 & 71.4 \\
\hline Shortness of breath & 76.2 & 41.8 & 25.8 & 86.8 & 37.1 & 79.5 & 48.0 & 71.2 \\
\hline Wheezing & 61.2 & 78.0 & 29.9 & 88.3 & 54.5 & 89.5 & 72.7 & 79.4 \\
\hline $\begin{array}{l}\text { Nocturnal awakening } \\
\text { due to breathlessness }\end{array}$ & 55.6 & 67.7 & 28.4 & 85.1 & 32.6 & 84.1 & 51.2 & 70.9 \\
\hline
\end{tabular}

Abbreviations: NPV, negative predictive value; PPV, positive predictive value. 

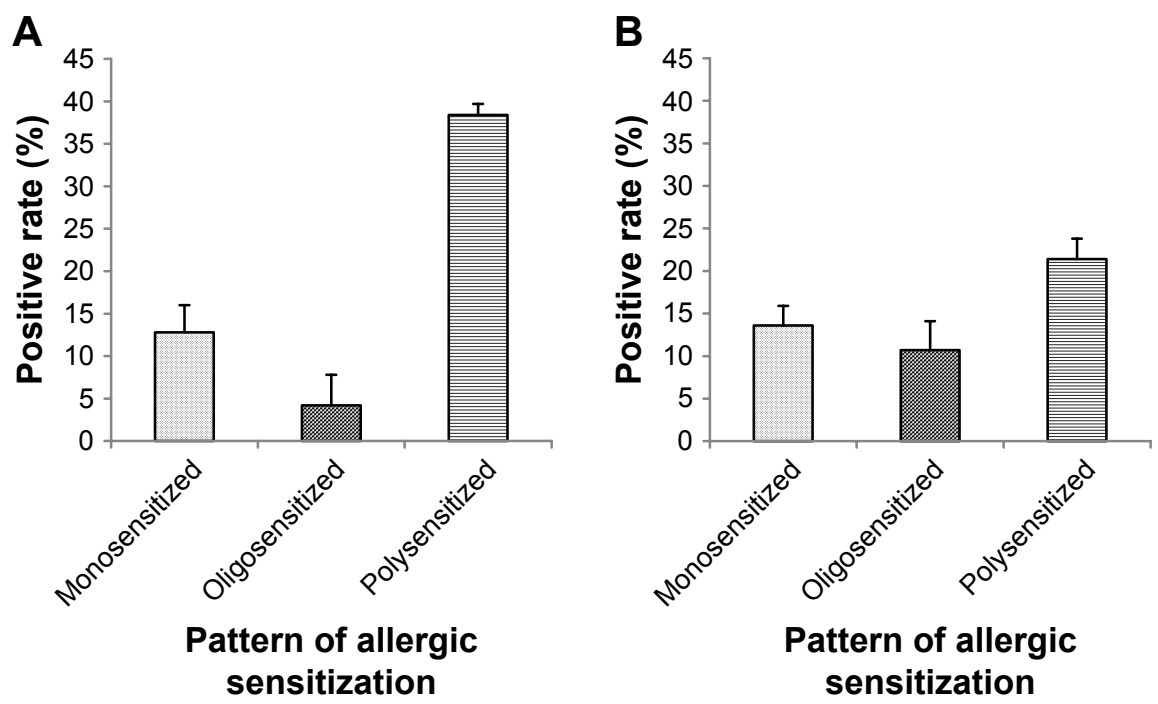

Figure 2 Pattern of allergic sensitization (by SPT) among adults (A) and children (B) sensitized to at least one allergen.

Notes: Monosensitized: sensitization to a single pollen allergen; oligosensitized: sensitization to two pollen allergens; polysensitized: sensitization to more than two pollen allergens.

Abbreviation: SPT, skin prick test.

Compared to the two studies described earlier, our study is novel because 1) it focuses on a unique phenotype of polleninduced seasonal asthma, 2) patients were diagnosed with asthma by respiratory specialists using a careful, systematic approach combining symptoms, lung function and SPTs and 3) both adult and pediatric patients were included in the study. By including both children and adults, we found that wheezing was more specific for, and predictive of, polleninduced asthma in children than in adults. One possible reason is that wheezing is a nonspecific symptom that can occur in a wide range of diseases, including COPD, bronchiectasis, endobronchial tumors, airway strictures, acute bronchitis and cardiac disease. These diseases increase in prevalence with increasing age and may explain the loss of specificity of wheezing for asthma in adults compared to children.

The optimal strategy for identifying pollen-induced asthma in adults in the setting of an epidemiological study remains unclear. The gold standard remains clinical assessment supplemented by spirometry and SPT positivity to pollen aeroallergens as in this study, but this approach is tedious and costly. Studies comparing symptoms versus symptoms supplemented by bronchoprovocation testing found that this led to increase in specificity but loss of sensitivity. Use of lung function tests and/or SPTs has important limitations: standardization is difficult especially in international studies, subjects may not be able to cooperate with the tests and their use may result in fewer participants. Future studies should take into account the potential pitfalls of using symptom questionnaires alone to identify asthma in adults, who may require additional evaluation either clinically, with lung function tests or tests of allergic sensitization to reliably identify cases. Our results do indicate that wheeze is a good marker of disease in children and can be a useful measure in epidemiological studies.

In this study, we have also reported the profile of symptoms experienced by patients with pollen-induced asthma, and how the symptoms wax and wane over time. In both adults and children, cough was the most frequently reported symptom. Previous studies of asthma, but not specifically polleninduced asthma, also found that cough was the most prevalent symptom. Zhang et a ${ }^{20}$ surveyed children with asthma in 30 Chinese cities and found cough was the most predominant symptoms (91.3\%), followed by wheezing (76.2\%). Lin et $\mathrm{al}^{21}$ arrived at similar conclusions in adult patients, where cough was found in $66.3 \%$. In a study involving multiple sites across six countries in the Asia-Pacific region, asthma accounted for one-third of patients seeking medical care for cough, ${ }^{8}$ confirming the magnitude of the burden of cough in asthma. Osman et $\mathrm{al}^{22}$ found that asthma patients rated cough as the symptom of the overriding concern. The current management for asthma emphasizes treating the underlying airway inflammation to reduce asthma symptoms but not specifically cough. Compared to other symptoms such as wheeze, chest tightness or dyspnea, cough may also respond less well to treatment with bronchodilators and cough is difficult to measure objectively in clinical practice. We propose that asthma patients may be well served by additional patient-centered interventions targeting cough. 
This study has several limitations. First, response of symptoms to asthma treatment was not assessed due to cross-sectional design of the study. Second, severity and intensity of symptoms were not evaluated and therefore their association with indices of disease severity could not be determined. Third, the perception and reporting of symptoms may be culture specific and language specific and may not be generalizable to other populations. Fourth, there was a high prevalence of smoking among adults presenting with respiratory symptoms, a group which may represent the forme fruste of COPD. Fifth, our study preferentially selects asthmatics who seek contact with health services. In the literature, some studies have shown the influences of meteorological parameters and biological and chemical air pollutants to the incidence of asthma, ${ }^{23-26}$ which are not investigated in this study and must be considered in our future studies.

\section{Conclusion}

Cough was the predominant symptom in pollen-induced asthma. Wheezing had good positive predictive value for diagnosing pollen-induced asthma in children, but respiratory symptoms were poorly predictive of pollen-induced asthma in adults. In adults, a systematic approach integrating the analysis of symptoms, exposure to pollen, objective measurement on lung function and allergic sensitization is needed to accurately diagnose pollen-induced asthma.

\section{Acknowledgment}

This study was supported by grants from the National Key Clinical Specialist Construction Programs of China.

\section{Author contributions}

Conception and design: TTM, XYW and HZS. Data collection: TTM and YZ. Data analysis and interpretation: TTM and HYG. Drafting the manuscript: TTM and ACY. Editing and final approval of the manuscript: TTM, ACY, XYW and HZS. All authors contributed toward data analysis, drafting and critically revising the paper and agree to be accountable for all aspects of the work.

\section{Disclosure}

The authors report no conflicts of interest in this work.

\section{References}

1. Masoli M, Fabian D, Holt S; Global Initiative for Asthma (GINA) Program. The global burden of asthma: executive summary of the GINA dissemination committee report. Allergy. 2004;59(5):469-478.

2. World Health Organization. Global Surveillance, Prevention and Control of Chronic Respiratory Diseases: A Comprehensive Report. Geneva: World Health Organization; 2007.
3. Horak F, Doberer D, Eber E, et al. Diagnosis and management of asthma - statement on the 2015 GINA guidelines. Wien Klin Wochenschr. 2016;128(15-16):541-554.

4. Loftus PA, Wise SK. Epidemiology and economic burden of asthma. Int Forum Allergy Rhinol. 2015;5(suppl 1):S7-S10.

5. Braman SS. The global burden of asthma. Chest. 2006;130(1 suppl): S4-S12.

6. Croisant S. Epidemiology of asthma: prevalence and burden of disease Adv Exp Med Biol. 2014;795:17-29.

7. Wong GW, Leung TF, Ko FW. Changing prevalence of allergic diseases in the Asia-pacific region. Allergy Asthma Immunol Res. 2013;5(5): 251-257.

8. Cho SH, Lin HC, Ghoshal AG, et al. Respiratory disease in the AsiaPacific region: cough as a key symptom. Allergy Asthma Proc. 2016; 37(2):131-140.

9. Global Initiative for Asthma [homepage on the Internet]. Global Strategy for Asthma Management and Prevention. 2017. Available from: www.ginasthma.org. Accessed June 26, 2017.

10. The International Study of Asthma and Allergies in Childhood (ISAAC) Steering Committee. Worldwide variations in the prevalence of asthma symptoms: the International Study of Asthma and Allergies in Childhood (ISAAC). Eur Respir J. 1998;12(2):315-335.

11. Asher MI, Montefort S, Björkstén B, et al; ISAAC Phase Three Study Group. Worldwide time trends in the prevalence of symptoms of asthma, allergic rhinoconjunctivitis, and eczema in childhood: ISAAC phases one and three repeat multicountry cross-sectional surveys. Lancet. 2006;368(9537):733-743.

12. Variations in the prevalence of respiratory symptoms, self-reported asthma attacks, and use of asthma medication in the European Community Respiratory Health Survey (ECRHS). Eur Respir J. 1996;9(4): 687-695.

13. Global Initiative for Asthma [homepage on the Internet]. Global Strategy for Asthma Management and Prevention. 2014. Available from: www.ginasthma.org. Accessed June 26, 2017.

14. Vogelmeier CF, Criner GJ, Martinez FJ, et al. Global strategy for the diagnosis, management, and prevention of chronic obstructive lung disease 2017 report: GOLD executive summary. Eur Respir J. 2017;49(3): 1700214.

15. D'Amato G, Vitale C, D'Amato M, et al. Thunderstorm-related asthma: what happens and why. Clin Exp Allergy. 2016;46(3):390-396.

16. Packe GE, Ayres JG. Asthma outbreak during a thunderstorm. Lancet. 1985;2(8448):199-204.

17. Darrow LA, Hess J, Rogers CA, Tolbert PE, Klein M, Sarnat SE. Ambient pollen concentrations and emergency department visits for asthma and wheeze. J Allergy Clin Immunol. 2012;130(3):630.e4-638.e4.

18. Bousquet J, Khaltaev N, Cruz AA, et al; World Health Organization; GA(2)LEN; AllerGen. Allergic rhinitis and its impact on asthma (ARIA) 2008 update (in collaboration with the World Health Organization, GA(2)LEN and AllerGen). Allergy. 2008;63(86 suppl):S8-S160.

19. Sistek D, Tschopp JM, Schindler C, et al. Clinical diagnosis of current asthma: predictive value of respiratory symptoms in the SAPALDIA study. Eur Respir J. 2001;17(2):214-219.

20. Zhang J, Dai J, Yan L, et al. Air pollutants, climate, and the prevalence of pediatric asthma in urban areas of China. Biomed Res Int. 2016;2016: 2935163.

21. Lin HC, Cho SH, Ghoshal AG, et al. Respiratory diseases and the impact of cough in Taiwan results from the APBORD observational study. Medicine (Baltimore). 2016;95(27):e3854.

22. Osman LM, Mckenzie L, Cairns J, et al. Patient weighting of importance of asthma symptoms. Thorax. 2001;56(2):138-142.

23. Ho WC, Hartley WR, Myers L, et al. Air pollution, weather, and associated risk factors related to asthma prevalence and attack rate. Environ Res. 2007;104(3):402-409.

24. Makra L, Tombácz S, Bálint B, Sümeghy Z, Sánta T, Hirsch T. Influences of meteorological parameters and biological and chemical air pollutants to the incidence of asthma and rhinitis. Clim Res. 2008;37(1): 99-119. 
25. Matyasovszky I, Makra L, Bálint B, Guba Z, Sümeghy Z. Multivariate analysis of respiratory problems and their connection with meteorological parameters and the main biological and chemical air pollutants. Atmos Environ. 2011;45(25):4152-4159.
26. Toshikazu A, Tokuda Y, Ohde S, Ishimatsu S, Nakamura T, Birrer RB. The relationship of short-term air pollution and weather to $\mathrm{ED}$ visits for asthma in Japan. Am J Emerg Med. 2009;27(2):153-159.

\section{Publish your work in this journal}

Therapeutics and Clinical Risk Management is an international, peerreviewed journal of clinical therapeutics and risk management, focusing on concise rapid reporting of clinical studies in all therapeutic areas, outcomes, safety, and programs for the effective, safe, and sustained use of medicines. This journal is indexed on PubMed Central, CAS,
EMBase, Scopus and the Elsevier Bibliographic databases. The manuscript management system is completely online and includes a very quick and fair peer-review system, which is all easy to use. Visit http://www.dovepress.com/testimonials.php to read real quotes from published authors.

Submit your manuscript here: http://www.dovepress.com/therapeutics-and-clinical-risk-management-journal 